\title{
Reflections on delivering interprofessional education in practice
}

\section{Sundari Joseph ${ }^{1}$, Lesley Diack ${ }^{2}$, Fiona Garton ${ }^{3}$, and Jenni Haxton ${ }^{4}$}

\begin{abstract}
The interprofessional education (IPE) programme in Aberdeen has been in existence since 2003. Commencing with undergraduate students from medicine and pharmacy, it expanded to include: applied biomedical science; diagnostic radiography; dietetics; midwifery; nursing; nutrition; occupational therapy; physiotherapy and social work. To cater for these different courses the programme has been diversified using blended learning strategies and innovative technologies. Models for practice delivery have been tried and tested, and research evidence has underpinned the development. This paper will highlight three of these tested models that can be used to deliver IPE in practice namely: simulation using gaming; face-to-face IPE in practice and the creation of virtual communities for student learning. A critical factor to enhancing the excellence of this curriculum development was the quality of the partnership working between the Universities and the practice settings. Fundamental to this was the staff development in IPE facilitation and training. Students demonstrated transferable skills from university to placement settings, applying their learning to interprofessional and inter-agency working. These formal and informal learning approaches have been crucial to the students' acceptance of each other as equal partners in delivering health and social care.
\end{abstract}

Keywords: interprofessional education; models of practice learning; curriculum development; gaming; placements; virtual communities

1. Senior Lecturer. Interprofessional Education Research, Robert Gordon University

2. Professor, Pharmacy and Life Sciences, Robert Gordon University

3. Head of GP teaching and locum GP, University of Aberdeen

4. Practice Education Facilitator, NHS Grampian

Address for correspondence: Robert Gordon University and University of Aberdeen. s.joseph@rgu.ac.uk 


\section{Background}

The theoretical base for interprofessional learning can be found in many academic disciplines including sociology, psychology, anthropology, philosophy, and political sciences. Drawing on adult learning theories and engaging in life experiences, the aim is to develop independent learners and critical thinkers who have the ability to work interprofessionally by articulating their own professional requirements to one another in an environment of mutual respect and trust. The Aberdeen IPE strategy builds on evidence from Diack et al (2008) and encompasses a multi-perspective approach to IPE developments. The aim was to develop practitioners who were confident and comfortable with their uni-professional identity and capable of embracing interprofessional collaboration and team working for the benefit of quality patient care.

\section{Adopting a theoretical framework}

The framework for IPE Aberdeen's pedagogy is adapted from Miller's (1990) Taxonomy and the CAIPE definition (CAIPE, 2002). This framework has been developed by the Canadian Institute for Health Information (http:// www.cihi.ca/CIHI-ext-portal/internet/EN/Home/home/cihi000001) and is highlighted in Figure 1.

The framework enables recognition of the learner's achievement of professional development on the 'novice' to 'expert' continuum. Similar to Bloom's Taxonomy of Objectives in the Cognitive Domain (1956), it encourages the development of complexity in interprofessional knowledge and skills as the learner engages with the programme. Adding value and application to Miller's taxonomy is the CAIPE definition (CAIPE, 2002) where the key components of learning 'with', 'from' and 'about' each other, ensure that this is interprofessional education and not shared or simply multiprofessional learning.

Setting IPE within a theoretical framework enables the curriculum designer to constructively align learning, teaching and assessment and be cognisant of the question 'what do we want the learner to do as a result of learning?' (Biggs and Tang, 2007). Addressing this question helped to establish knowledge, skills and attitudes learning outcomes for pre and

33 J. of Practice Teaching \& Learning 13(2-3), pp.32-44. @ w\&b 

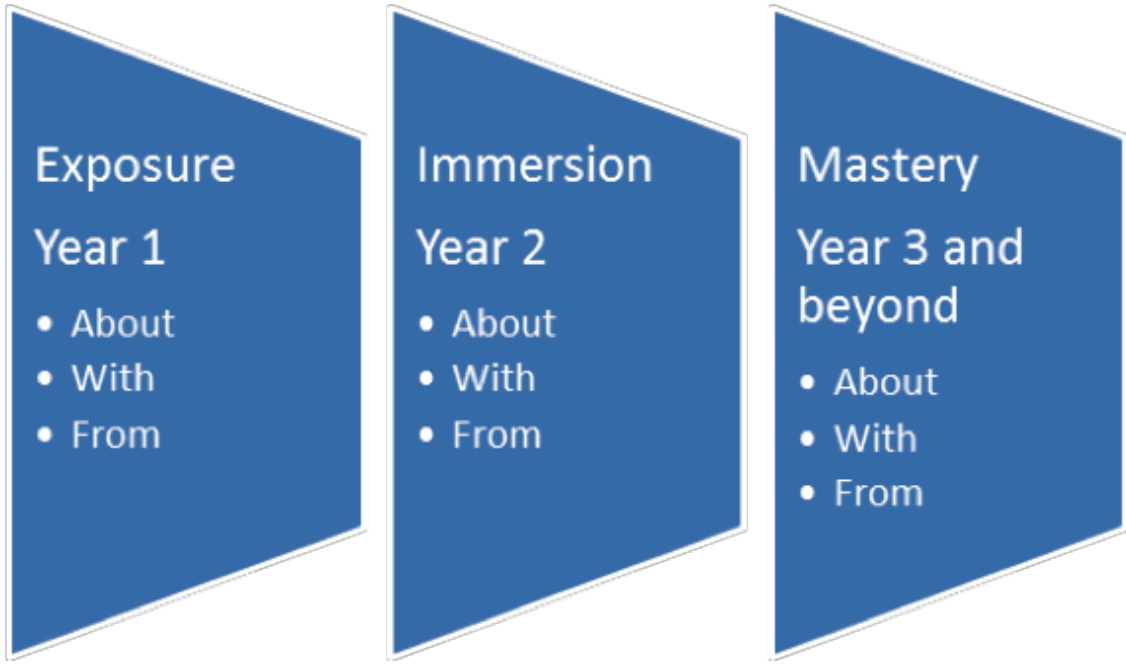

Figure 1: Miller's Taxonomy.

post qualifying IPE curriculum development (Freeth et al, 2005). The competencies identified by Barr (1998) were embedded into IPE in practice placements, correlating with placement assessment documentation for many of the courses involved.

The IPE in practice strategy was developed based on the strengths of these theoretical perspectives. This strategy was complementary and built on the learning approaches for classroom based IPE in years one and two of 17 undergraduate courses from the following professions: applied biomedical science; diagnostic radiography; dietetics; medicine; midwifery; nursing; nutrition; occupational therapy; pharmacy; physiotherapy and social work (approx. 1000 students per cohort). Students participated in IPE sessions that 'exposed' and 'immersed' them to the ideas, concepts and values of working interprofessionally. Promoting IPE in Practice was an important priority within this and by year 3 they were ready to apply their earlier learning and began their development in the 'mastery' of interprofessional working.

34 J. of Practice Teaching \& Learning 13(2-3), pp.32-44. ๑ wEb 


\section{Model 1: Simulation using gaming - Preparation for practice learning}

An innovative interprofessional game, iPEG was first used in classroom based IPE and has flexibility to be adapted into practice locations (Joseph and Diack, 2014). It was designed to enable the understanding of professional roles and responsibilities in patient/client care settings. The game encapsulates fun and memorable learning styles to explore professional stereotypes and team approaches to care delivery. Loosely based around the premise of Monopoly ${ }^{\mathrm{TM}}$ (see Figure 2) the iPEG uses 'discussion' and 'task' cards to engage students and explore professional roles. It comprises real case scenarios with vignettes on each discussion card that build in complexity as the game progresses. The iPEG can be played in many different ways and is flexible to adapt to the contextual needs of players.

It has been used successfully for three cohorts of first year students within the Aberdeen IPE programme. Group student evaluation was completed at the end of the iPEG sessions using a survey tool designed by the authors with numeric and text-based elements. Data indicated $90 \%$ agreement for learning outcome achievement $(n=1400)$. Staff evaluation questionnaires were completed and reflective feedback on student perceptions was included in facilitator training sessions. Ninety per cent of staff $(n=55)$ evaluated the game positively.

The game is best played in mixed groups with different professions represented. It can be played with students from different educational backgrounds ranging from first year to final year undergraduates. The iPEG can be adapted to classroom or placement settings. The authors have implemented the iPEG in undergraduate courses, in different countries and languages, in non healthcare settings and as an ice breaker at conference workshop presentations with educators.

\section{Translating playing into learning: the skill of the facilitator}

Students can perceive games simply as a playful exercise with no significant learning (Stephens, Abbott-Brailey and Pearson, 2007). Analysis of the students' text-based comments identified a minority who expressed a lack of understanding regarding the purpose of the game. The skill of the

35 J. of Practice Teaching \& Learning 13(2-3), pp.32-44. (๑) w\&b 


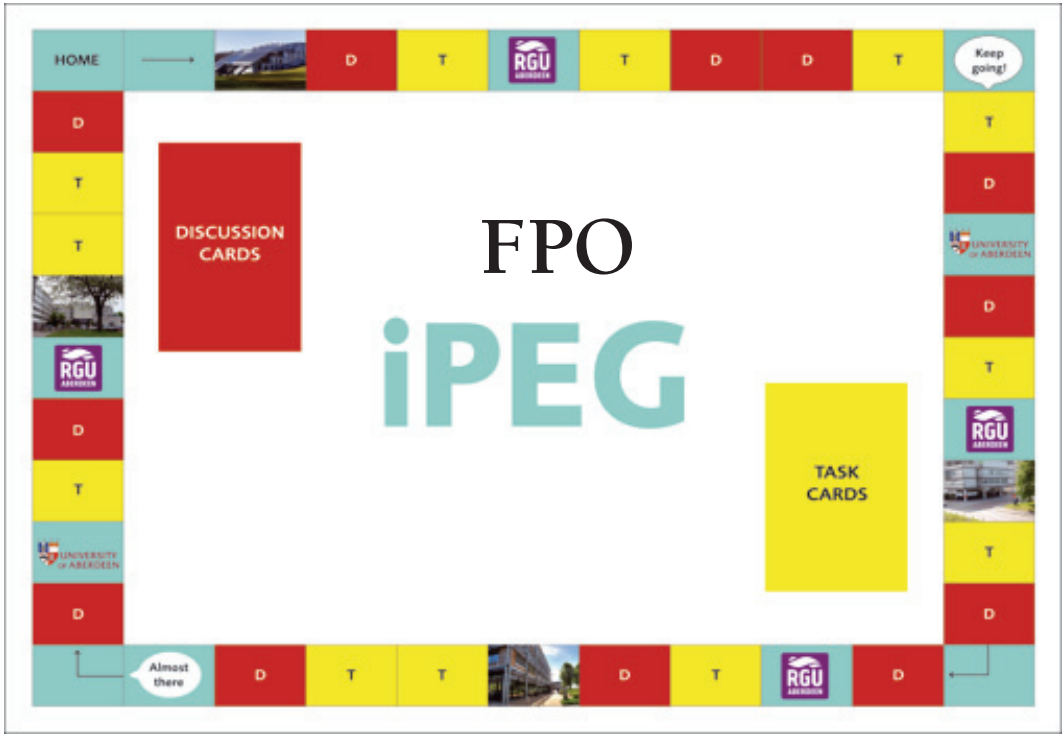

Figure 2: ${ }_{\text {PEG }}$

facilitator is crucially important to translate the experience from 'playing to learning'. Effective facilitation is also acknowledged to be a crucial part of successful IPE (Freeth, Hammick, Reeves, Koppel and Barr, 2005). The key elements involved in facilitating a 'serious' game are briefing and debriefing. This separates the game from becoming a playful task and emphasises the learning outcomes as essential. Facilitators therefore create a connection for students from learning in the game and their application of the skills learnt in other situations (McClarty et al, 2012). When playing the iPEG the facilitators 'framed' the game experience as education enabling students to focus on the interprofessional outcomes. Developing facilitators' skills in practice required strong partnership working with university and practice colleagues.

\section{Partnership working for successful IPE in practice}

The partnership working between the two Aberdeen Universities and the NHS is paramount to the success of IPE in Practice and has been long established. In 2003 a joint working group between the two universities began the development of an IPE programme. Further enhancements

36 J. of Practice Teaching \& Learning 13(2-3), pp.32-44. ( $w \mathcal{E} b$ 
occurred with the involvement of NHS partners in creating scenarios for the events. This relationship building between the IPE lead and key practice partners led to innovative developments in IPE. It was imperative that a collaborative process to the design of IPE development was undertaken involving, educators, clinicians, and service users where possible. This ensured ownership of the development within practice and that the examples given to students were realistic and therefore maintain quality learning experiences and quality patient/client care. In time students' and service user contribution to the development of learning activities were incorporated in the evaluation process. These initiatives incorporated staff development as a vital component for effective IPE facilitation training with practitioners and academics. This further enhanced the quality assurance of IPE delivery.

The approach adopted by IPE Aberdeen is different to other universities, as it recognised that every placement experience is an IPE opportunity. Learning can be acquired from good and bad experiences of interprofessional working using a 'student and practice led' model. IPE in practice had two dimensions, face to face IPE with students in practice locations meeting each other and secondly the IPE Tool Kit for Practice for real case selection. The two dimensions were separate strategies but occurred concurrently. This enabled ease of delivery for students whose placements are very diverse, from city based locations to remote and rural, highlands and islands.

\section{Model 2: Face-to-face IPE in practice locations}

Students from different disciplines engaged in IPE whilst on their placement location. An IPE educational forum was created in each practice location. This consisted of practice staff with an educational remit meeting together with the IPE lead to identify the type of educational input that could be designed in their location. It required sharing of information regarding student availability and numbers of students; the design of the activity; facilitation and evaluation. There were six locations that developed interprofessional learning in this way (See Table 1).

During the first year, 148 students experienced face-to-face IPE in practice. They completed an amended version of the Readiness for

37 J. of Practice Teaching \& Learning 13(2-3), pp.32-44. @ w\&b 
Table 1: Locations and Topics for IPE in Placement Settings

\begin{tabular}{|c|c|c|}
\hline Location & Topic & Professions \\
\hline $\begin{array}{l}\text { General Theatres } \\
\text { Aberdeen Royal } \\
\text { Infirmary }\end{array}$ & $\begin{array}{l}\text { Patient safety issues } \\
\text { in the peri-operative } \\
\text { journey }\end{array}$ & $\begin{array}{l}\text { Medicine, Nursing, } \\
\text { Pharmacy }\end{array}$ \\
\hline $\begin{array}{l}\text { Royal Cornhill } \\
\text { Hospital }\end{array}$ & $\begin{array}{l}\text { Old Age Psychiatry- } \\
\text { ward based case study }\end{array}$ & $\begin{array}{l}\text { Dietetics; Medicine; } \\
\text { Nursing; Occupational } \\
\text { Therapy; Physiotherapy; } \\
\text { Clinical Psychology; } \\
\text { Social Work }\end{array}$ \\
\hline Woodend Hospital & $\begin{array}{l}\text { Elderly Triage and Ward } \\
\text { based case study }\end{array}$ & $\begin{array}{l}\text { Medicine, Nursing, } \\
\text { Occupational Therapy }\end{array}$ \\
\hline $\begin{array}{l}\text { Blood Transfusion } \\
\text { Centre }\end{array}$ & $\begin{array}{l}\text { Sample pathway from } \\
\text { patient to laboratories to } \\
\text { patient }\end{array}$ & $\begin{array}{l}\text { Biomedical Science; } \\
\text { Medicine; Nursing }\end{array}$ \\
\hline City Hospital & $\begin{array}{l}\text { Elderly Rehabilitation } \\
\text { Ward based case study }\end{array}$ & $\begin{array}{l}\text { Dietetics; Nursing; } \\
\text { Occupational Therapy; } \\
\text { Physiotherapy; Social } \\
\text { Work }\end{array}$ \\
\hline Health Centre & $\begin{array}{l}\text { Case study allocated } \\
\text { from case load }\end{array}$ & $\begin{array}{l}\text { Medicine; Nursing; } \\
\text { Occupational Therapy; } \\
\text { Physiotherapy; } \\
\text { Pharmacy; Social Work }\end{array}$ \\
\hline
\end{tabular}

InterProfessional Learning Scale (RIPLS) (Parsell and Bligh, 1999) before and after the activity evaluating the impact on student's perceptions of learning together, and the relationship as future practitioners. Students could also comment on the IPE activity itself within the open questions.

The RIPLS questionnaire feedback from those students who returned both before and after questionnaires $(n=73)$, demonstrated significant differences in attitudinal change between responses pre and post the IPE activity on placement for 16 out of 19 questions relating to student learning $(\mathrm{p}<0.001)$. The example from general theatres relating to patient safety is highlighted below.

38 J. of Practice Teaching \& Learning 13(2-3), pp.32-44. @ wEb 


\section{Example of face-to face activity: Patient safety}

The practice education facilitator from nursing, medical practitioner and IPE lead worked together to design the activity. Participants were medical, nursing, and pharmacy students during their practice placement in the general theatre area of a large hospital. Students were asked to reflect on their experiences of patients' journeys from ward, theatre, and recovery areas. The learning outcomes focussed on students recognising each profession's roles and responsibilities in relation to the patient's perioperative checks for a surgical procedure; have an understanding of the 'surgical briefing and pause' procedures (Scottish Patient Safety Programme, 2008) and knowing which checks are in place in the ward, theatre and recovery. They attended a two hour facilitated session and shared their experiences. They engaged in an activity to identify errors in mock documentation and medication charts. For many, this was the first time they had seen each other's documentation. The session ended by focussing on communication, teamwork, shared decision making and a reflection of their learning.

It was important to evaluate the learning achieved and ethical approval was granted from both universities for pre and post RIPLS questionnaire administration.

\section{Mean scores for pre and post RIPLS responses}

Figure 3 shows the mean scores before and after the IPE activity. Questions $10,11,12,18$ and 19 have means well below the neutral level of 3 both before and after the activity, showing strong levels of disagreement with the question asked. All other questions have means well above the neutral level of three, showing strong levels of agreement. Fourteen out of 19 questions indicated strong levels of agreement.

This approach to IPE in Practice is novel and innovative and has been recognised as contributing significantly in the field and has validated the effectiveness of this model for delivering IPE in practice (Joseph et al 2012).

39 J. of Practice Teaching \& Learning 13(2-3), pp.32-44. (C) wEb 


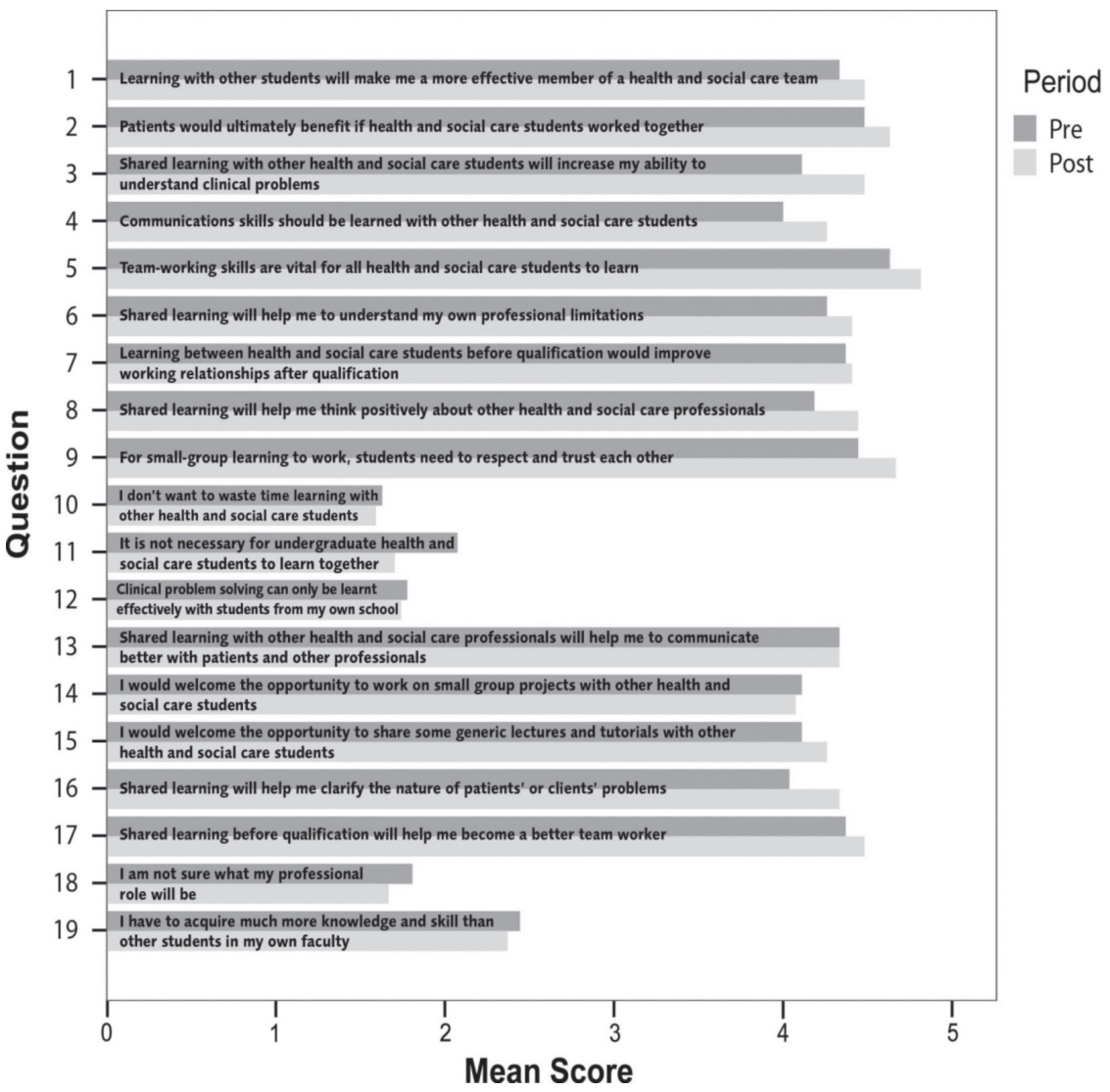

Figure 3: Theatre study.

\section{Model 3: Virtual communities for student learning - Toolkit for Practice}

To scale up the numbers involved in IPE in placement locations and bring some parity to the 1000 students per cohort, a toolkit for real case selection was designed. Using Web 2.0 technology and the Virtual Learning Environment (VLE) students were allocated to interprofessional buddy groups, simulating communities of practice in placement. They participated in professional exchanges related to a self-selected case whilst on placement. To engage with students from different disciplines they each posted a synopsis of their case to their virtual 'IPE buddy group' discussion forum and posed specific questions to the other professions. This occurred for the first time with 
4 professions undertaking summative assessments linked with this activity (midwifery; nursing; occupational therapy and physiotherapy). The statistics from the university's VLE for this first year of activity were very positive with a total student interaction of 30,269 hits to the forum and total student postings were 6,442 which included 206 different discussion topics. While it would be beneficial for this toolkit to be used by all professional student groups there are barriers to its implementation. These are issues of placement timing, and reliance on students' voluntary cooperation during busy study times.

For successive years the activity was amended based on student and facilitator feedback and more courses became involved including, dietetics; social work and diagnostic radiography. However assessment by all courses proved more difficult to achieve with only 5 courses using the toolkit to summatively assess interprofessional working in practice.

One of the advantages of this model for IPE in practice was that it introduced real patients/clients to students who do not have many placement opportunities e.g. pharmacy students and enabled real cases to be discussed by all students in the IPE programme.

Figure 4 highlights the process for student engagement with the IPE tool kit.

\section{Sustaining facilitation of IPE in Practice}

The role of the facilitator in IPE remains crucial to learning. The educational forums that were created in practice were bespoke groups comprising educators from many different disciplines and included location specific professions. The key function of these groups was to plan, implement, facilitate and evaluate IPE within their practice locations by focussing on real cases. Practice colleagues were trained on facilitation techniques and addressing the challenges involved in mixed group facilitation. Following this initial training a cascade approach was adopted where an experienced facilitator from practice and a novice facilitator implemented an IPE activity and after the event gave each other feedback on their facilitation experience. Their anecdotal reflections suggested that they enjoyed the experience and an unexpected outcome for them was the realisation that their team had developed into a more cohesive and effective team. These

41 J. of Practice Teaching \& Learning 13(2-3), pp.32-44. @ wE-b 
- Consider a complex or challenging patient/client/carer situation you are involved with in your clinical/practice placement.

- Analyse the wide range of needs that makes this particular situation complex or challenging.

- Identify any questions you have with regard to interprofessional involvement in this specific situation.

- Seek an opportunity to work with at least one of these students or professional in the practice environment with regard to these questions.

- Use this interaction to evaluate your questions and identify what queries you still may have with regard to interprofessional working in this patient/client situation.

- Summarise a short synopsis of the patient/client and their care/treatment in around 300 words.

- Ensure that you adhere strictly to rules of anonymity and confidentiality i.e. identity and location should not be disclosed

- Include any information gathered from your experience of working with or talking to other professions in the placement setting.

Formulate your own questions/themes that you would like to be discussed with students of other professional groups.

- These may be with regard to further optimising this client/patient's care and treatment or be related to professional/ethical issues you have identified.

Moodle site for comments from students in other professions.

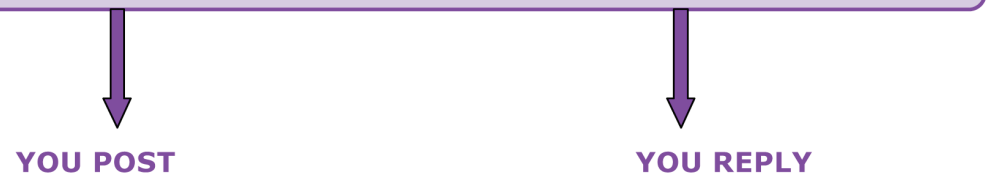

Figure 4: Student Led Tool Kit for IPE in Practice Locations. 
facilitators have since shared their experiences of IPE activity development at local conferences, encouraging more practice colleagues to undertake IPE in practice.

\section{Conclusion}

This paper has described three different models for IPE in practice settings based on the overall approach within the two universities in Aberdeen. It has introduced the relevance of simulation using gaming in IPE curriculum design; the importance of face-to-face contact between students from different professions in placement locations and the development of a virtual infrastructure that enabled larger numbers of students to engage with placement IPE. These have received positive evaluations and are recommended as examples for IPE educators designing curricula. The importance of IPE facilitator training was crucial to the successful delivery of these models and required commitment from practice staff. Using the conceptual framework students were able to progress from exposure; immersion and mastery in the IPE learning outcomes set. They considered the uniqueness of their own professional role and what that brings to real cases but at the same time appreciated, understood and respected the roles and responsibilities of other professionals. It was only in sharing this with each other that their similarities and differences were understood and that it required 'learning with from and about each other' (CAIPE 2002) i.e. not shared or common learning but true IPE.

\section{References}

Barr, H. (1998) Competent to collaborate: Towards a competency-based model for interprofessional education. Journal of Interprofessional Care, 12, 2 181-187 [online] Available from: http://informahealthcare.com/doi/ abs/10.3109/13561829809014104 [Accessed 12 ${ }^{\text {th }}$ March 2015].

Biggs, J. and tang, C. (2007) Teaching for Quality Learning at University Maidenhead: Open University Press/McGraw-Hil

Blooms, B. (1956) Blooms Taxonomy of Objectives in the Cognitive Domain. [online] Available from:http://ww2.odu.edu/educ/roverbau/Bloom/blooms_taxonomy.

43 J. of Practice Teaching \& Learning 13(2-3), pp.32-44. @ w\&b 
htm [Accessed 12th March 2015]

Centre for the Advancement of Interprofessional Education (CAIPE) (2002) [online] Available from: http://www.caipe.org.uk/about-us/definingipe/?ke ywords=definition [Accessed $5^{\text {th }}$ Feb 2015]

Diack, L., Gibson, M., Healey, T., Bond, C. and Mackenzie, H. (2008) The Aberdeen Interprofessional Health and Social Care Initiative- Final report. [online] Available from:http://www.ipe.org.uk/ [Accessed 5 ${ }^{\text {th }}$ Feb 2015]

Freeth, D., Hammick, M., Reeves, S., Koppel, I., and Barr, H. 2005. Effective interprofessional education. Oxford:Blackwell

Joseph, S. and Diack, L. (2014) Playing interprofessional games: Reflections on Using the Interprofessional Education Game (iPEG). Journal of Interprofessional Care,. pp 1-3 [Online] Available from: http://informahealthcare.com/doi/full/10 .3109/13561820.2014.942839

Joseph, S., Diack, L., Haxton, J. and Garton, F. (2012) Interprofessional Education in Practice., Clinical Teacher. 9, 1, 27-31 pdf/Interprofessional education in practice Clinical Teacher Jan12.pdf

McClarty, K.L., Orr, A., Frey, P.M., Dolan, R.P.,Vassileva, V. and McVay, A. (2012. A literature review of gaming in education. Research report. Gaming in Education. Available from http://researchnetwork.pearson.com/wp-content/uploads/ Lit_Review_of_Gaming_in_Education.pdf [Accessed 5th Feb 2015]

Parsell G. and Bligh J. (1999) The development of a questionnaire to assess the readiness of health care students for interprofessional learning (RIPLS), Medical Education, 33, 95-100. Amended RIPLS found at: http://www.ipe.org.uk

Scottish Patient Safety Programme. (2008). Scottish Patient Safety Alliance, NHS Scotland [online] Available from: http://www.patientsafetyalliance.scot.nhs. uk/ [Accessed 16 ${ }^{\text {th }}$ March 2015].

Stephens, J., Abbott-Brailey, H. And Pearson, P. (2007) 'It's a funny old game'. Football as an educational metaphor within induction to practice-based interprofessional learning. Journal of Interprofessional Care, 21, 4, 375-385

44 J. of Practice Teaching \& Learning 13(2-3), pp.32-44. ๑ w\&b 